\title{
Formulation and Evaluation of Ondansetron HCl Nanoparticles for Transdermal Delivery
}

Amjed H. Noor ${ }^{*, 1}$ and Mowafaq M. Ghareeb**

* Ministry of Health and Environment, Babylon Health Directorate, Babylon, Iraq. ** Department of Pharmaceutics, College of Pharmacy, Baghdad University, Baghdad, Iraq

\section{Abstract}

Ondansetron $\mathrm{HCl}$ (OND) is a potent antiemetic drug used for control of nausea and vomiting associated with cancer chemotherapy. It exhibits only $60-70 \%$ of oral bioavailability due to first pass metabolism and has a relative short half-life of 3-5 hours. Poor bioavailability not only leads to the frequent dosing but also shows very poor patient adherence. Hence, in the present study an approach has been made to develop OND nanoparticles using eudragit ${ }^{\circledR}$ RS100 and eudragit ${ }^{\circledR}$ RL100 polymer to control release of OND for transdermal delivery and to improve patient compliance.

Six formulas of OND nanoparticles were prepared using nanoprecipitation technique. The particles sizes and zeta potential were measured using zeta-plus analyzer. The particle morphology was also studied using scanning electron microscopy (SEM). The in-vitro release of the drug from the nanoparticles was carried out in phosphate buffer saline $\mathrm{pH} 7.4$.

The particle size of the prepared NPs were in nano size which ranged from (95.34 to 275.84 $\mathrm{nm})$ with positive zeta potential. The drug entrapment efficiency was varied with the drug polymer ratio from $41.87 \%$ to $78.45 \%$. The SEM showed uniform shape and regularly distributed particle sizes. The in-vitro drug release study exhibited the sustained release of OND with burst release. The cumulative percentage released after $12 \mathrm{hr}$. were between were 77.89 and $96.01 \%$.

Also the transdermal permeation study show that nanoparticles permeate more efficiently than aqueous solution of the drug through the skin by approximately two fold. OND nanoparticles were prepared successfully using nanoprecipitation method. The controlled drug release aimed for transdermal drug delivery could be obtained by using eudragit RS100 and eudragit RL100 polymers which can reduce dosing frequency, decrease side effects and improve patient compliance.

Keywords: Ondansetron HCl, Nanoprecipitation method, Eudragit RS100, Eudragit RL100, SEM.

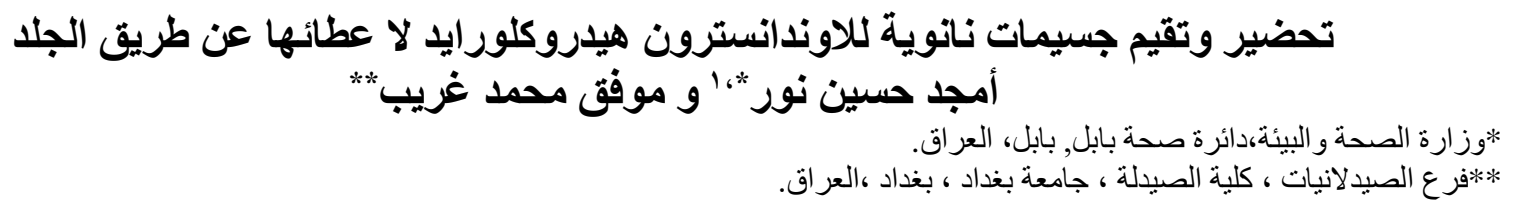

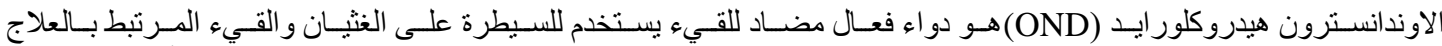

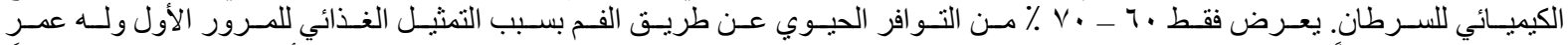

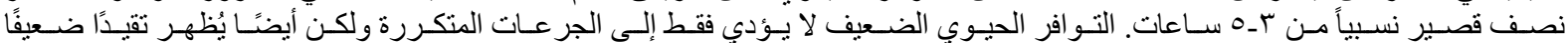

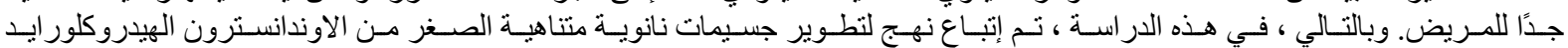

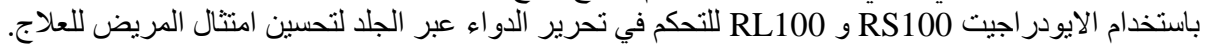

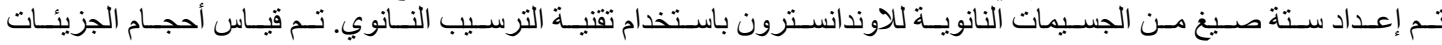

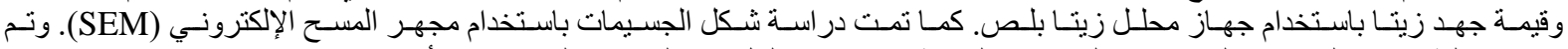

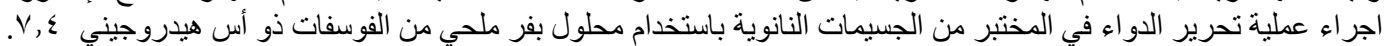

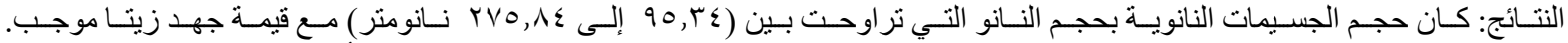

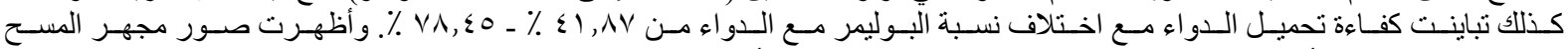

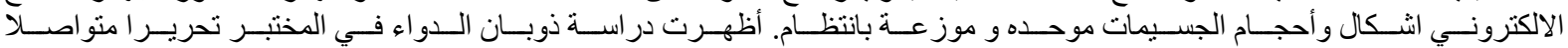

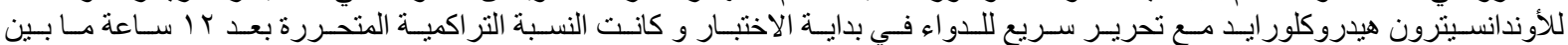

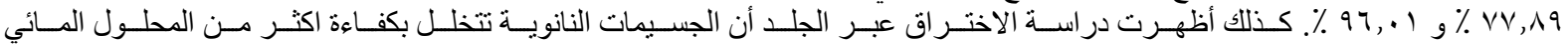

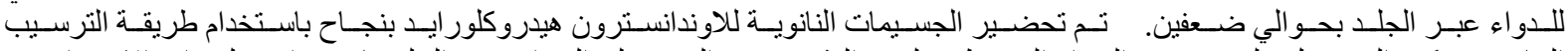

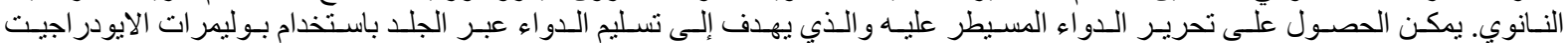

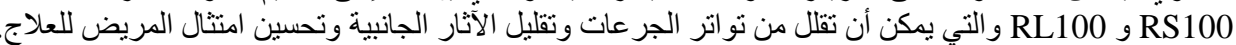

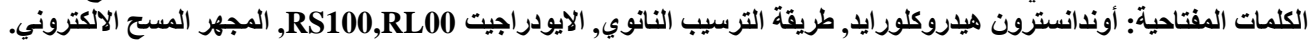

${ }^{1}$ Corresponding author E-mail: amjadnoor29@yahoo.com

Received: 22/12/2019

Accepted: 3/5 /2020

Iraqi Journal of Pharmaceutical Science 


\section{Introduction}

Nanoparticles (NPs) offer a number of advantages for dermal drug delivery, including improved drug solubility and stability, adjustable surface properties, increased surface adhesion, drug targeting, controlled drug release and increased drug penetration and permeation through the skin and mucus membrane $\mathrm{e}^{(1)}$.

Nanoparticle surface charge has a significant effect on adhesion and penetration of nanoparticles through the skin and mucus membrane. The skin is negatively charged under normal physiological conditions and positively charged nanoparticles may adhere to it. Cationic amino- Eudragit nanoparticles penetrated deeper into the skin in comparison to negatively charged nanoparticles. This is attributed to lack of electrostatic interaction with negatively charged nanoparticles that impaired access to the outermost skin layer ${ }^{(2,3)}$.

The most common form of drug delivery is the oral route; this route of administration has notable advantages and also have significant drawbacks like first pass metabolism, drug degradation in gastrointestinal tract due to enzymes, $\mathrm{pH}$ etc. To overcome these difficulties a novel drug delivery system was developed. In recent years it has been shown that the skin is a suitable route for drug delivery to the systemic circulation $^{(4)}$.

The skin has been an essential route for drug delivery when topical, local, or systemic effects are preferred. However, skin constitutes an excellent barrier and presents difficulties for the transdermal delivery of therapeutic agents, since limited drugs possess the features necessary to penetrate throughout the stratum corneum in adequate amounts to reach a therapeutic concentration in the blood ${ }^{(5)}$.

In order to enhance drug transdermal absorption, various strategies have been considered, developed, and patented. Development in physical permeationenhancement technologies has led to renewed interest in transdermal drug delivery. Some of these novel technologies include iontophoresis, electroporation, ultrasound, microneedles to open up the skin, and more recently the use of transdermal nanocarriers ${ }^{(6)}$.

Transdermal drug delivery system (TDDS) includes all topically administered drug preparations intended to deliver the active ingredients into the circulation $^{(7)}$. TDDS can improve the therapeutic efficacy and safety of drugs by more precise spatial and temporal employment of the drug within the body thereby decreasing both the size and number of doses and also improving its effectiveness with optimal dose concentrations. Appropriate drug choice and an effective drug delivery system play an essential role in achieving optimal therapeutic results ${ }^{(8)}$.

Ondansetron $\mathrm{HCl}$ a 5HT3 antagonist is a potent antiemetic drug used for control of nausea and vomiting associated with cancer chemotherapy (Figure 1). It exhibits only $60-70$ $\%$ of oral bioavailability due to first pass metabolism and has a relative short half-life of 3-5 $\mathrm{hr}^{(9)}$.

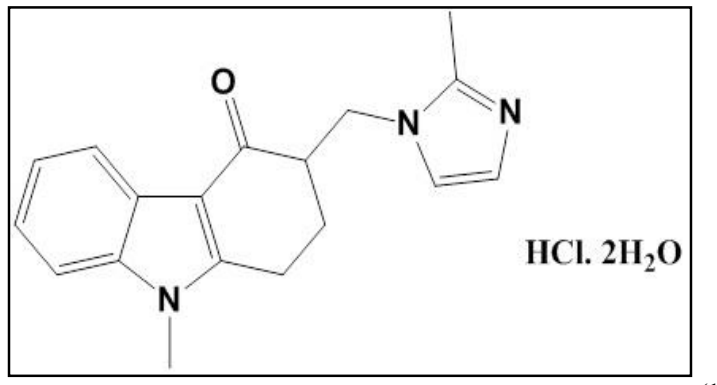

Figure 1. Chemical structure of Ondansetron $\mathrm{HCl}^{(10)}$

The objective of this study is to formulate and evaluate of OND nanoparticles for transdermal drug delivery and to improve patient compliance.

\section{Materials and Methods \\ Materials}

Ondansetron $\mathrm{HCl}$ (gift from pioneer Co. for pharmaceutical industries) polyvinyl alcohol (PVA), Eudragit RS 100 (Rhom pharma, Germany) and Eudragit RL 100 (Rhom pharma, Germany), ethanol (Thomas Baker chemical, Mumbai, India). All other chemicals used were of analytical grade.

\section{Methods}

\section{Preparation of OND nanoparticles}

Six formulas of OND nanoparticles were prepared using solvent/ antisolvent precipitation technique (Nanoprecipitation method). A certain amount of pure drug of OND and polymer was completely dissolved in water miscible solvent (ethanol). The obtained drug-polymer solution was then injected at speed of $0.5 \mathrm{~mL} / \mathrm{min}^{(11)}$ using syringe infusion pump into the water containing stabilizer (1\% PVA) with continuous stirring of $1000 \mathrm{rpm}$. Precipitation of solid drug particles occurred immediately upon mixing. The precipitated nanoparticles are sonicated for $5 \mathrm{~min}$ using probe sonicator. The organic solvent was then evaporated under room temperature and then lyophilized using freeze drying system (Copley, UK) to obtain the nanoparticles powder. The composition and variable condition of preparation of different formulas of nanoparticles are listed in Table (1) ${ }^{(12)}$. 
Table 1. Composition of OND nanoparticles

\begin{tabular}{|c|c|c|c|c|c|}
\hline $\begin{array}{c}\text { Code } \\
\text { No. }\end{array}$ & $\begin{array}{c}\text { OND } \\
(\mathbf{m g})\end{array}$ & Eudragit RL 100(mg) & $\begin{array}{c}\text { Eudragit RS 100 } \\
(\mathbf{m g})\end{array}$ & PVA \% & D:P Ratio \\
\hline F1 & 8 & & 8 & 1 & $1: 1$ \\
\hline F2 & 8 & & 16 & 1 & $1: 2$ \\
\hline F3 & 8 & 8 & 24 & 1 & $1: 3$ \\
\hline F4 & 8 & 16 & & 1 & $1: 1$ \\
\hline F5 & 8 & 24 & & 1 & $1: 2$ \\
\hline F6 & 8 & & & & $1: 3$ \\
\hline
\end{tabular}

\section{Characterization of OND nanoparticles \\ Particle size analysis}

Particle size distribution, mean diameters, and polydispersity index of nanoparticles were determined by dynamic light scattering (DLS) techniques using particle size analyzer (ZetaPlus, Brookhaven, USA) at a scattering angle of $90^{\circ}$ at room temperature. For each sample, measurements were achieved in triplicate ${ }^{(13)}$.

\section{Zeta potential}

It is a physical property in suspension. It is defined as the difference between the bulk solution (dispersing medium) and the surface of the hydrodynamic shear (slipping plane). It can be used to optimize the nanoparticle formulation for long time stability. It was measured by zeta-plus analyzer (ZetaPlus, Brookhaven, USA) (14). Measurements were performed in triplicate.

\section{Surface morphology}

The morphological examination of the nanoparticles was performed using scanning electron microscopy (SEM; TESCAN, UK) ${ }^{(15,16)}$.

\section{Entrapment efficiency $(E E)$ :}

Weighed samples of drug-loaded nanoparticles $(10 \mathrm{mg})$ were dissolved in $10 \mathrm{~mL}$ of methanol under sonication for $2 \mathrm{hr}$. The samples were filtered through a membrane filter and analyzed spectrophotometrically at $\lambda_{\max } 310 \mathrm{~nm}$ using a UV/Vis spectrophotometer (EMC LAB, Germany). The entrapment efficiency was determined using the following equation ${ }^{(15)}$;

$$
\% E E=\frac{\text { mass of drug in nanoparticles }}{\text { mass of drug used in preparation }} \times 100
$$

The measurements were performed in triplicate and values were the mean \pm SD.

\section{In vitro drug release studies}

Four milliliter of nanodispersion $(8 \mathrm{mg}$ drug) were placed in dialysis bags (8000-14000 D), which were sealed and placed in $500 \mathrm{~mL}$ dissolution medium (phosphate buffer $\mathrm{pH} \quad 7.4$ containing $0.25 \%$ brij-35). Drug release study was carried out employing the USP type II dissolution apparatus (Pharma test, Germany) at $37{ }^{\circ} \mathrm{C} \pm 0.5$ and $50 \mathrm{rpm}$ for $20 \mathrm{hr}$. At each time interval of $1,2,3,4,5,6,7,8,9,10,11,12$ and 20 hr. aliquots $5 \mathrm{~mL}$ of sample was collected and replaced with fresh buffers. The collected samples were analyzed spectrophotometrically at $\lambda_{\max } 310$ $\mathrm{nm}$ (17). The measurements were performed in triplicate and values were the mean \pm SD.

\section{In-vitro skin permeation study}

The abdominal skin of adult male wistar rats weighing $250 \pm 10 \mathrm{~g}$ obtained from animal house of College of Pharmacy/ University of Baghdad were used for in-vitro permeation study of nanoparticles.

The rat skin was fixed between the donor and receptor compartment with the stratum corneum facing upper side of the inverted glass tube in beaker (modified diffusion cell). To maintain sink conditions $100 \mathrm{~mL}$ phosphate buffer $\mathrm{pH} 7.4$ containing $0.25 \%$ (w/v) brij-35 were added in receptor chamber. The temperature was maintained at $37 \pm 1^{\circ} \mathrm{C}$. receptor media was continuously stirred with magnetic stirrer at 50 rpm, in a way that the rat skin surface just flushes the diffusion fluid. The formulation $(4 \mathrm{~mL})$ was gently placed in a donor compartment. At time interval of $1,2,3,4,5,6,7,8$ and $12 \mathrm{hr}$ aliquots of $2 \mathrm{~mL}$ sample were withdrawn from the receptor compartment and replaced as soon as possible with the same volume of receptor fluid. The samples were analyzed for drug content using UV spectrophotometer at $\lambda_{\max } \quad 310 \quad \mathrm{~nm}$. Each experiment was performed in triplicate. The cumulative amount of drug permeated (Q) at different time intervals and various parameters like steady-state flux $\left(\mathrm{J}_{\mathrm{ss}}\right)$, lag time $\left(\mathrm{T}_{\mathrm{L}}\right)$ and apparent permeation coefficient $\left(\mathrm{P}_{\text {App }}\right)$ were calculated ${ }^{(18)}$. The measurements were performed in triplicate and values were the mean \pm SD. 


\section{Compatibility study}

\section{Fourier Transform \\ Infrared Spectroscopy} (FTIR)

Before the development of formulation, FTIR spectra of physical mixtures of OND with polymers were compared with the standard FTIR spectrum of the pure drug (OND) were performed using FTIR spectroscopy (Alpha II, Bruker, Germany). Spectra were recorded between 400 and $4000 \mathrm{~cm}^{-1}$ range ${ }^{(19)}$.

\section{Thermal analysis: Differential Scanning Calorimetry (DSC)}

DSC analysis was performed using thermal analysis instrument (STD Q600 V20.9 Build 20, USA). The samples (pure drug, physical mixture and selected formula) were weight $(4 \mathrm{mg})$ in a sealed aluminum pans and heated at a rate of 10 ${ }^{\circ} \mathrm{C} / \mathrm{min}$ in a 30 to $350{ }^{\circ} \mathrm{C}$ temperature under nitrogen flow of $40 \mathrm{~mL} / \mathrm{min}^{(20)}$.

\section{Powder X-ray Diffractometric (PXRD) Study}

The powder $X$-ray diffraction configuration of the achieved sample of the OND was determined to confirm the crystalline nature of the drug. The study was confirmed using powder Xray diffractometery (XRD-6000, Shimadzu, Japan $220 \mathrm{~V} / 50 \mathrm{~Hz})$; the operating voltage and current were $40(\mathrm{kV})$ and $30(\mathrm{~mA})$ respectively. Samples were scanned at $2 \theta$ from $0-80^{\circ}$ for qualitative studies and the scanning rate was $4 \% \mathrm{~min}^{(21)}$.

\section{Statistical Analysis}

The outcomes of the experimental work are demonstrated as a mean of triplicate models \pm SD and were examined in relation to the one-way analysis of variance (ANOVA) to determine if the changes in the applied factors are statistically significant at level of $(\mathrm{P}<0.05)$ and nonsignificant at level of ( $\mathrm{p}>0.05)$.

\section{Results and Discussion}

Ondansetron $\mathrm{HCl}$ loaded nanoparticles were prepared by Nano-precipitation method without using toxic harmful organic solvents. Additionally, this method has an advantage of single step, no need of high shear/ stirring rate or high temperature. This technique is suitable for compounds that are soluble in ethanol or acetone.

Two grades of eudragit polymer, (eudragit RS 100 and eudragit RL 100) were used. Although both show $\mathrm{pH}$-independent drug release properties, they differ in their water permeability. eudragit RS100 has very low water permeability, while eudragit RL100 has high water permeability ${ }^{(22)}$. Additionally, the ability of eudragit polymers to form nanodispersion with smaller particle size, positive surface charge (due to the quaternary ammonium groups on the polymer surface) excellent stability, and lacking of irritant effect are advantageous. Eudragit ${ }^{\circledR}$ RL 100 has great water permeability, due to the higher quaternary ammonium group content than eudragit RS100 which allowed more water penetration and, consequently, more drug wetting and release ${ }^{(23)}$.

The effect of drug: polymer ratio exhibited a wide effect on particle size and distribution $(\mathrm{P}<$ 0.05). All the formulas confirmed a small mean particle size. The mean particle size varied from 95.34 to $275.84 \mathrm{~nm}$ with polydispersity index ranging from 0.271 to 0.367 (Table 2), the results showed that increasing the concentration of the dissolved polymer leading to increase the viscosity of organic phase and reduced the stirring efficiency resulted in the formation of the bigger emulsion droplets which lead to give larger particle size. The same results were recorded by Meltem C. et $\mathrm{al}^{(24)}$.

Type of polymer had no significant effect on particle size $(p>0.05)$ for all formulation. Both types of polymer gave nanoparticles with practically same particle size range, these outcomes were in agreement with Aisha, et al. ${ }^{(25)}$.

All formulations with Eudragit showed a positive zeta potential due to present of quaternary ammonium group (Figure 6) with values ranging from +15.72 to $+31.69 \mathrm{mV}$ (Table 2 ).

Table 2. Mean Particle size, PDI, Zeta potential and Entrapment Efficiency of OND Nanoparticles

\begin{tabular}{|c|c|c|c|c||}
\hline $\begin{array}{c}\text { Formulas } \\
\text { Code }\end{array}$ & Particle Size* $(\mathbf{n m})$ & PDI* & $\begin{array}{c}\text { Zeta Potential* } \\
(\mathbf{m V})\end{array}$ & $\begin{array}{c}\text { Entrapment } \\
\text { Efficiency* }\end{array}$ \\
\hline F1 & $95.340 \pm 13.24$ & $0.271 \pm 0.012$ & $+15.72 \pm 0.67$ & $48.93 \pm 0.63$ \\
\hline F2 & $136.69 \pm 21.67$ & $0.278 \pm 0.020$ & $+23.98 \pm 1.44$ & $73.76 \pm 0.77$ \\
\hline F3 & $246.43 \pm 24.21$ & $0.267 \pm 0.021$ & $+19.19 \pm 1.37$ & $78.45 \pm 2.13$ \\
\hline F4 & $111.66 \pm 18.45$ & $0.367 \pm 0.035$ & $+18.01 \pm 1.81$ & $41.87 \pm 1.54$ \\
\hline F5 & $145.670 \pm 9.56$ & $0.312 \pm 0.041$ & $+23.93 \pm 1.26$ & $65.12 \pm 1.64$ \\
\hline F6 & $275.84 \pm 27.13$ & $0.253 \pm 0.035$ & $+31.69 \pm 1.13$ & $71.72 \pm 1.32$ \\
\hline
\end{tabular}

*Average \pm Standard Deviation $(\mathrm{n}=3)$

Poly vinyl alcohol (PVA) is a water soluble, synthetic polymer, used in this preparation assists dual purposes; Firstly, it acts as a non-ionic surfactant and prevents the particle growth. Secondly, it maintains the viscosity of the preparation required for improve stability of nanoparticles. 
The entrapment efficiency of the drug was ranged from $41.87 \%$ to $78.45 \%$ for the prepared formulations. The results showed that the entrapment efficiency of the prepared nanoparticles was improved by increasing the ratio of polymer $(\mathrm{P}<0.05)$. It has been displayed that increase in polymer ratio in organic phase improves drug entrapment due to increase in viscosity of organic phase which enables the diffusional resistance of drug molecules from organic phase to aqueous phase, leading to entrapping greater quantity of drugs in the $\mathrm{NPs}^{(3)}$.

In vitro drug release profile of the prepared NPs using dialysis membrane at beginning showed a quick release characteristic of OND unrelated to the processing conditions. The release curve exhibited that initially fast release up to 30 min and then controlled release was achieved. Rapid release at the beginning may due to free, unencapsulated and adsorbed drug on the surface of the NPs. Drug release was slow from RS 100 compared to RL 100 nanosuspension and this may be due to the greater aqueous permeability of eudragit RL100 polymer. The release rate was correlated to the ratio of drug and polymer. The in vitro drug release profile of the formulations (F2, F3, F5 and F6) were 85.02\%, $77.89 \%, 96.01 \%$ and $82.69 \%$, respectively for $12 \mathrm{hr}$. Hazender and Dortunc also detected unlike drug release profiles when eudragit RL 100 was used in place of eudragit RS $100^{(26)}$. Generally, all the prepared nanoparticle formulas exhibited a sustained release and burst effect that could be detected (Figure 2). It suggests that percent drug release is dependent on the type of polymer used.

On the basis of particles size, encapsulation efficiency and release profile, batches F2 and F5 were chosen to complete other study to select the optimized batch for the preparation of nanoparticles.

Table 3. Permeation parameters of Ondansetron $\mathrm{HCl}$

\begin{tabular}{|c|c|c|c||}
\hline Formulation & $\begin{array}{c}\text { Flux* }\left(\mathbf{J}_{\mathbf{s s}}\right) \\
\left(\boldsymbol{\mu g} / \mathbf{c m}^{\mathbf{2}} \mathbf{~ h r}\right)\end{array}$ & $\begin{array}{c}\text { Permeability coefficient* }(\mathbf{P}) \\
(\mathbf{c m} / \mathbf{h r})\end{array}$ & $\begin{array}{c}\text { Lag time* }\left(\mathbf{t}_{\mathbf{L}}\right) \\
(\mathbf{h r})\end{array}$ \\
\hline F2 & $177.93 \pm 5.32$ & $8.9 * 10^{-2} \pm 0.003$ & $0.47 \pm 0.021$ \\
\hline F5 & $163.12 \pm 4.67$ & $8.1 * 10^{-2} \pm 0.0024$ & $0.76 \pm 0.063$ \\
\hline Aqueous solution & $80.44 \pm 4.12$ & $4 * 10^{-2} \pm 0.0013$ & $1.16 \pm 0.14$ \\
\hline
\end{tabular}

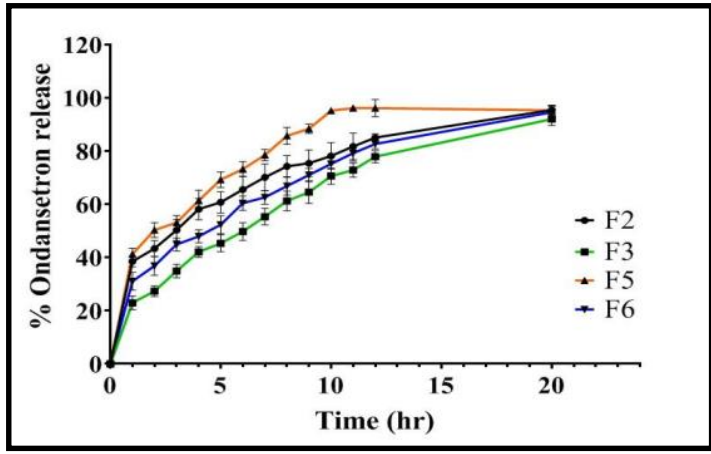

Figure 2. Dissolution profile of the prepared OND nanoparticles (F2,F3,F5 and F6) in PBS (pH 7.4).

The in vitro permeation study of the formulation F2 and F5 in comparing with the aqueous drug solution using rat skin show a significant improvement $(\mathrm{P}<0.05)$ in the penetration of OND (Figure 3). The flux $\left(\mathrm{J}_{\mathrm{ss}}\right)$ values for OND nanoparticles (F2 and F5) were 177.93and $163.12 \mu \mathrm{g} / \mathrm{cm}^{2} . \mathrm{hr}$ respectively, and for aqueous drug solution was $80.44 \mu \mathrm{g} / \mathrm{cm}^{2} \mathrm{hr}$.

Polymeric OND nanoparticles permeation was found to be higher than that for aqueous drug solution. The higher flux and permeation values of nanoparticles suggest that it might be able to cross the skin easily as compared with the aqueous drug solution.

The permeation profiles of OND nanoparticles (F2 and F5) and aqueous drug solution are shown in Figure 3. The permeated parameters such as steady state flux rate, lag time and apparent permeability coefficient $\left(\mathrm{P}_{\mathrm{App}}\right)$ are given in (Table 3 ). The total flux of nanoparticles was approximately two times higher than that of aqueous drug solution ${ }^{(27)}$.

The permeation study indicating that F2 gave the highest drug penetration with lowest lag time $(\mathrm{p}>0.05)$ in comparison with F5 and aqueous solution of the drug, so, it was chosen as the selected formula.

\section{*Average \pm Standard Deviation $(n=3)$}

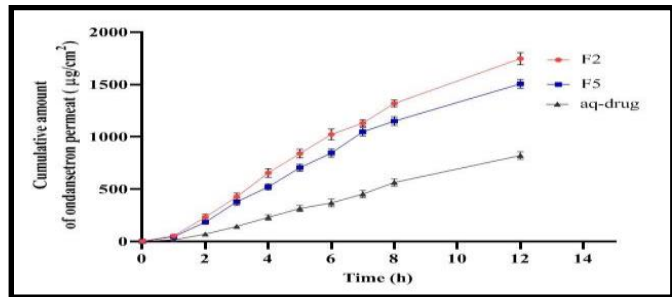

SEM (Figure 4) photograph of the selected formula (F2) exposed that OND loaded NPs have uniform shape and regularly distributed particle size which are correlated with the results obtained by zeta plus analyzer.

Figure 3. Permeation profiles of OND through rat skin from F2, F5 and aqueous drug solution 


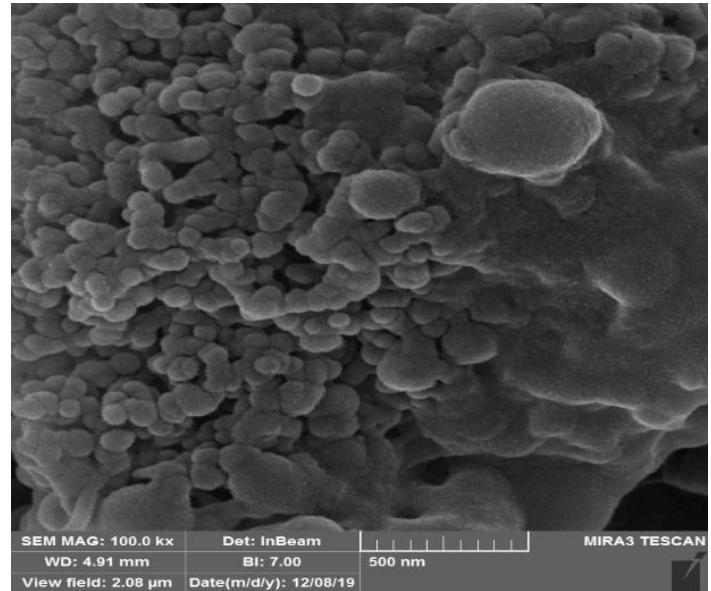

Figure 4. SEM of selected OND nanoparticles (F2)

The thermal analysis is an important method to decide any likely interaction between the drug and excipients used. Two endotherms peaks were achieved with $\mathrm{OND}$ at $202.53^{\circ} \mathrm{C}$ for drug melting and $111.46{ }^{\circ} \mathrm{C}$ (28) which corresponds to the dehydration process in OND, since it is a dihydrate (Figure 5).

The relatively decreased intensity of the endothermic peaks (Figure 6) in physical mixture may be due to dilution effect with small shift in melting point of $3.16{ }^{\circ} \mathrm{C}$ indicating that there is no interaction between the drug and the polymer, the same result was recorded by Pattnaik S. et al. ${ }^{(29)}$

In DSC thermogram of OND loaded nanoparticles (Figure 7), endothermic melting peak of drug at $202.53^{\circ} \mathrm{C}$ was completely disappeared, which indicate OND entrapment, presence of OND as molecularly dispersed form, and reduction in drug crystallinity in the nanoparticles matrix due to the solvent evaporation process, the same outcome were recorded by Kharb V. et al ${ }^{(21)}$.

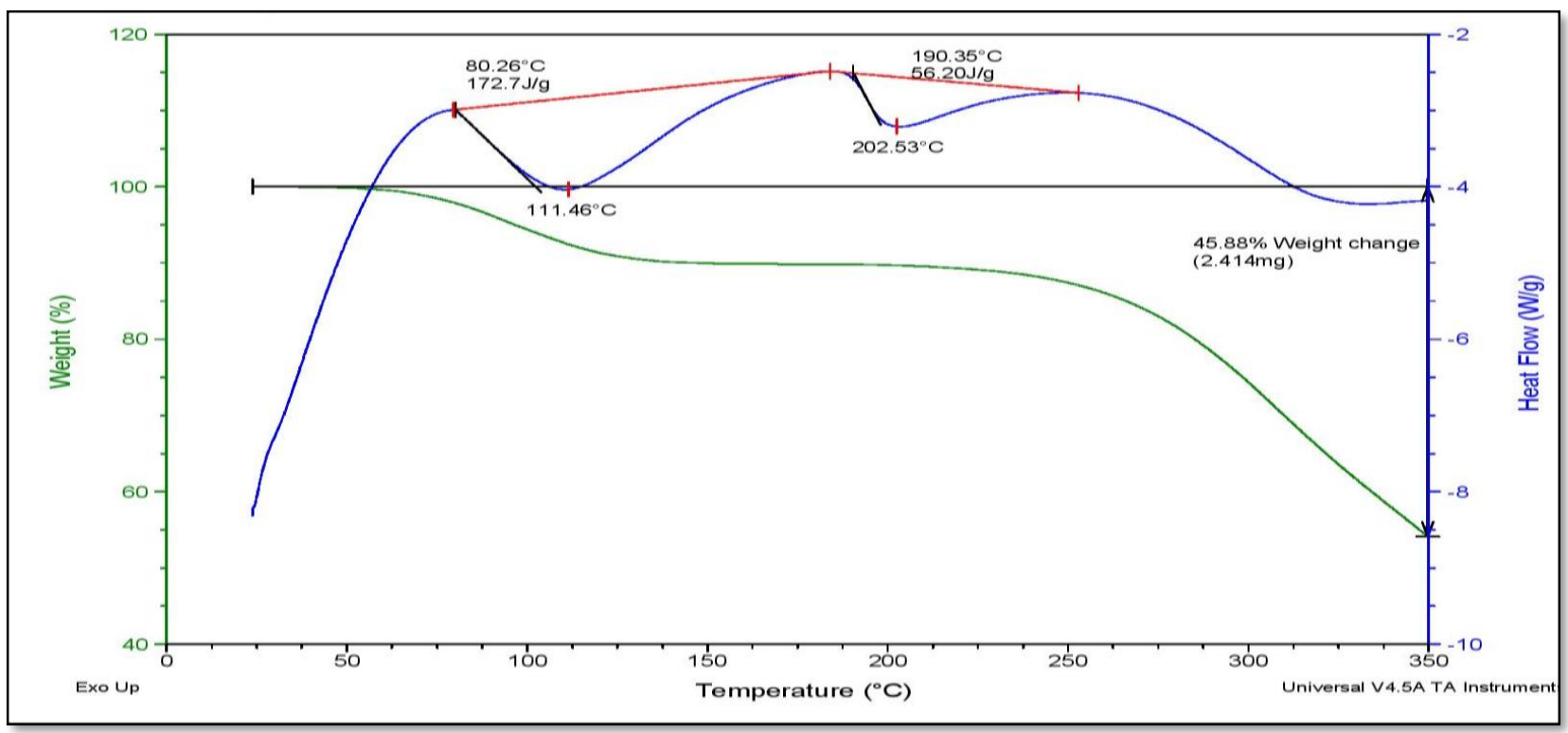

Figure 5. DSC of OND pure drug

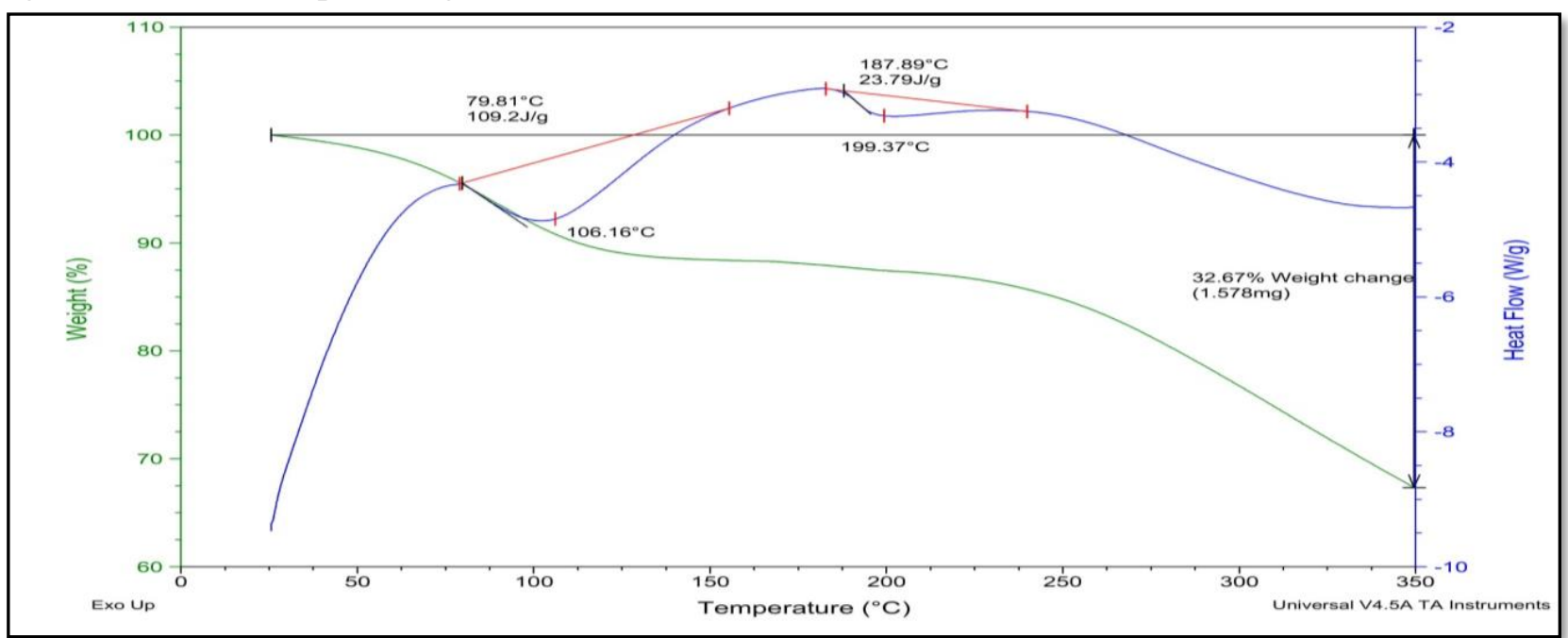

Figure 6.DSC of physical mixture (OND and Eudragit RS 100) 


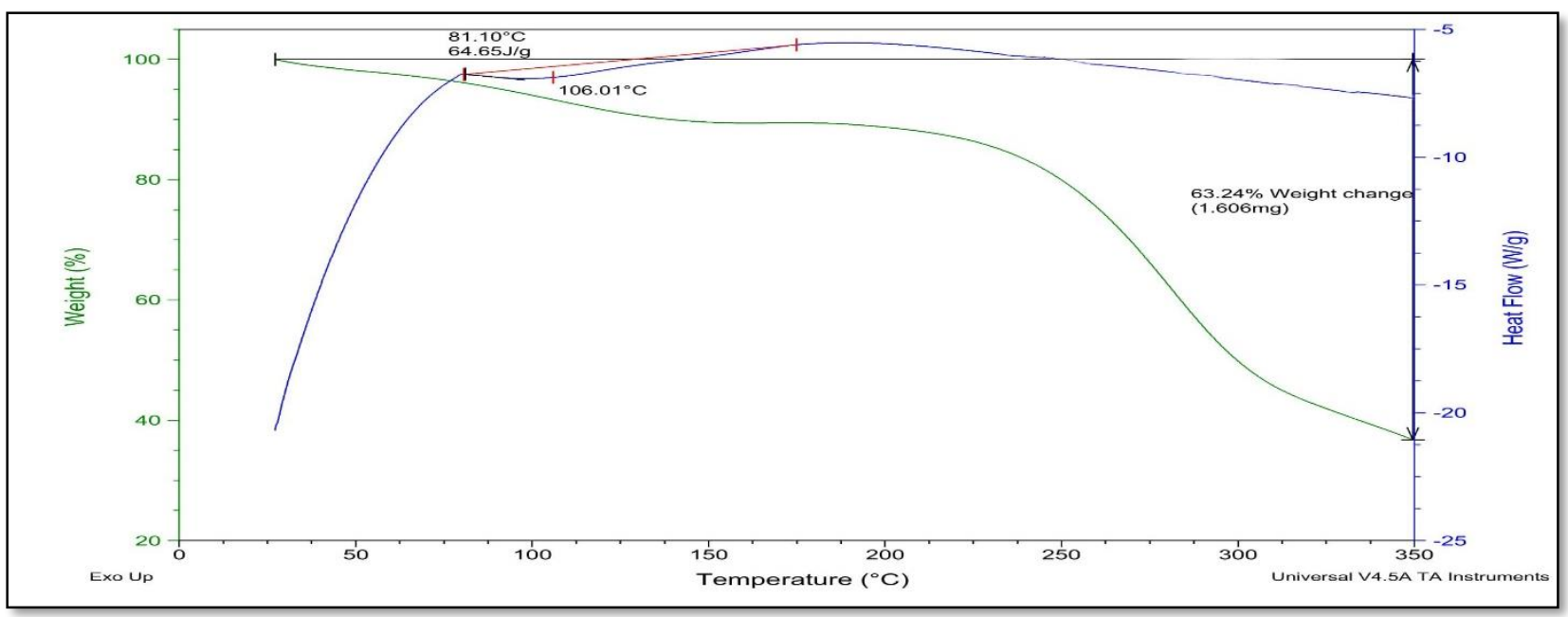

Figure 7. DSC of OND nanoparticles

X-ray diffractogram of OND (Figure 8-A) shows sharp high intensity peaks at diffraction angles $2 \Theta$ of $6^{\circ}$, $11.96^{\circ}, 16.42^{\circ}, 18.2^{\circ}, 24^{\circ}, 25.52^{\circ}$ and $30.1^{\circ}$ indicating that the drug is crystalline. XRD diffraction pattern of drug- polymer physical mixture (Figure 8-B) shows several characteristic sharp peaks of OND with reduced intensity which can be attributed to mixing process. This proved that OND was still present in crystalline form in the physical mixture and no drug polymer interaction occurred. XRD analysis of OND-loaded nanoparticles did not show any characteristic peaks of OND at its particular diffraction angle and the absence of peaks suggested the absence of crystallinity i.e. amorphous form in OND nanoparticles (Figure 8-C).

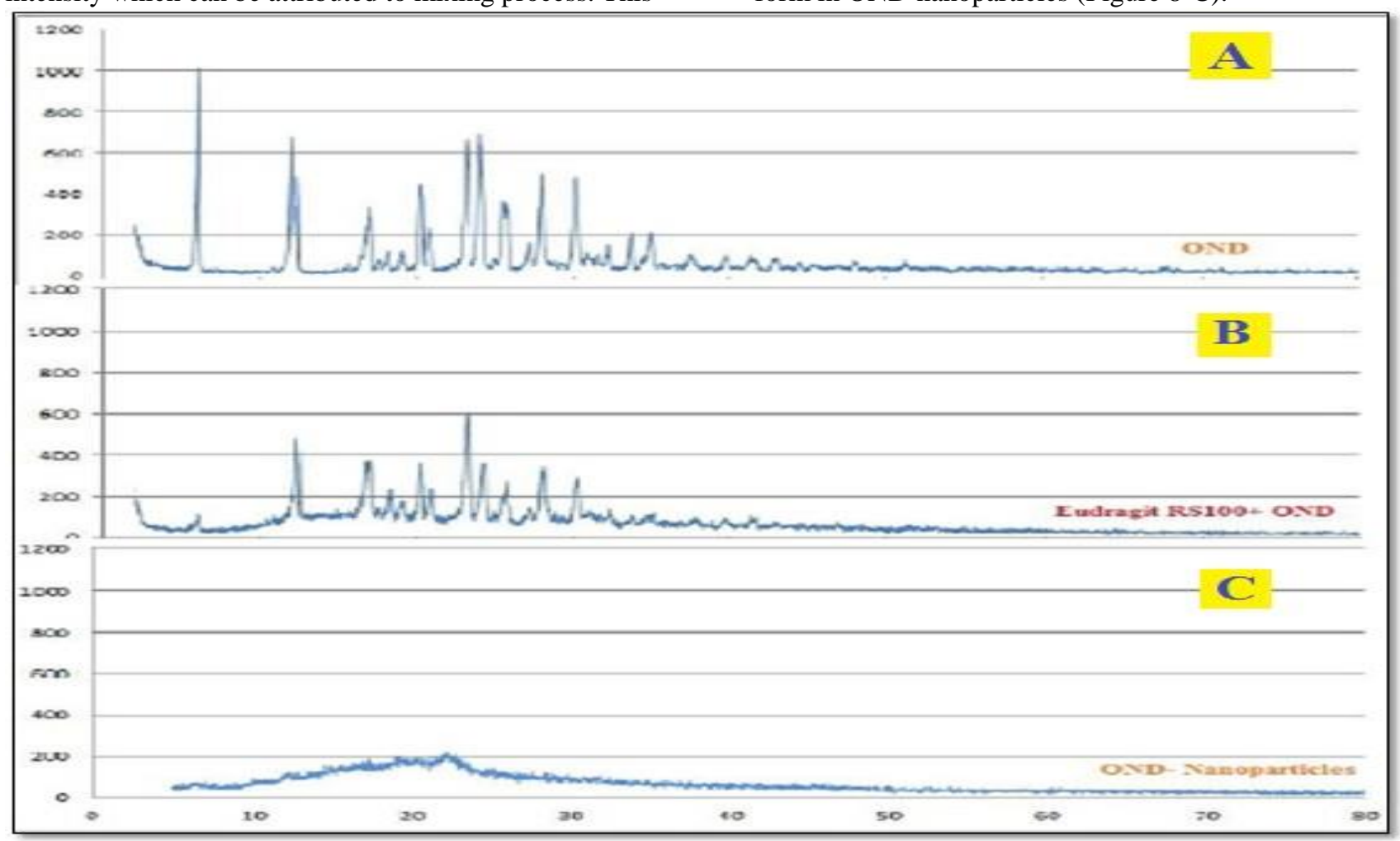

Figure 8. XRPD of (A) ONS, (B) physical mixture of OND and Eudragit RS100 and (C) Selected formula (F2) of OND- NPs 


\section{Fourier Transform Infrared Spectroscopy} (FTIR)

The IR spectra of the pure drug exhibits spectra at $3398.67 \mathrm{~cm}^{-1}$ (OH stretching), 1632.5 $\mathrm{cm}^{-1}(\mathrm{C}=\mathrm{O}$ stretching $)$ and at $754.54 \mathrm{~cm}^{-1}(\mathrm{C}-\mathrm{H}$ bending). The spectra of physical mixtures of the drug with polymers shows simple shifting in position and intensity of characteristic peeks specially for $\mathrm{OH}$ stretching of OND-PVA physical mixture which is due to $\mathrm{H}$-bond formation (Table 4 ), these outcomes indicating the compatibility of the drug with the polymers used in the formulation of nanoparticles (Figures 9- 11).

Table 4 . Characteristic peak of pure drug and physical mixture

\begin{tabular}{|c|c|c|c|c|}
\hline \hline NO. & Type of Peak & $\begin{array}{c}\text { Pure Drug } \\
\left(\mathbf{c m}^{-\mathbf{1}}\right)\end{array}$ & $\begin{array}{c}\text { OND-eudragit RS } \\
\text { Physical mixture } \\
\left(\mathbf{c m}^{-\mathbf{1}}\right)\end{array}$ & $\begin{array}{c}\text { OND- PVA } \\
\text { Physical mixture } \\
\left(\mathbf{c m}^{-\mathbf{1}}\right)\end{array}$ \\
\hline $\mathbf{1}$ & OH Stretching & 3398.67 & 3400.64 & 3373.36 \\
\hline $\mathbf{2}$ & C=O stretching & 1632.5 & 1633.48 & 1632.32 \\
\hline $\mathbf{3}$ & C-N stretching & 1080.77 & 1082.34 & 1081.56 \\
\hline $\mathbf{4}$ & C=N stretching & 1453.36 & 1453.97 & 1452.49 \\
\hline $\mathbf{5}$ & CH bending & 754.54 & 755.56 & 755.44 \\
\hline
\end{tabular}

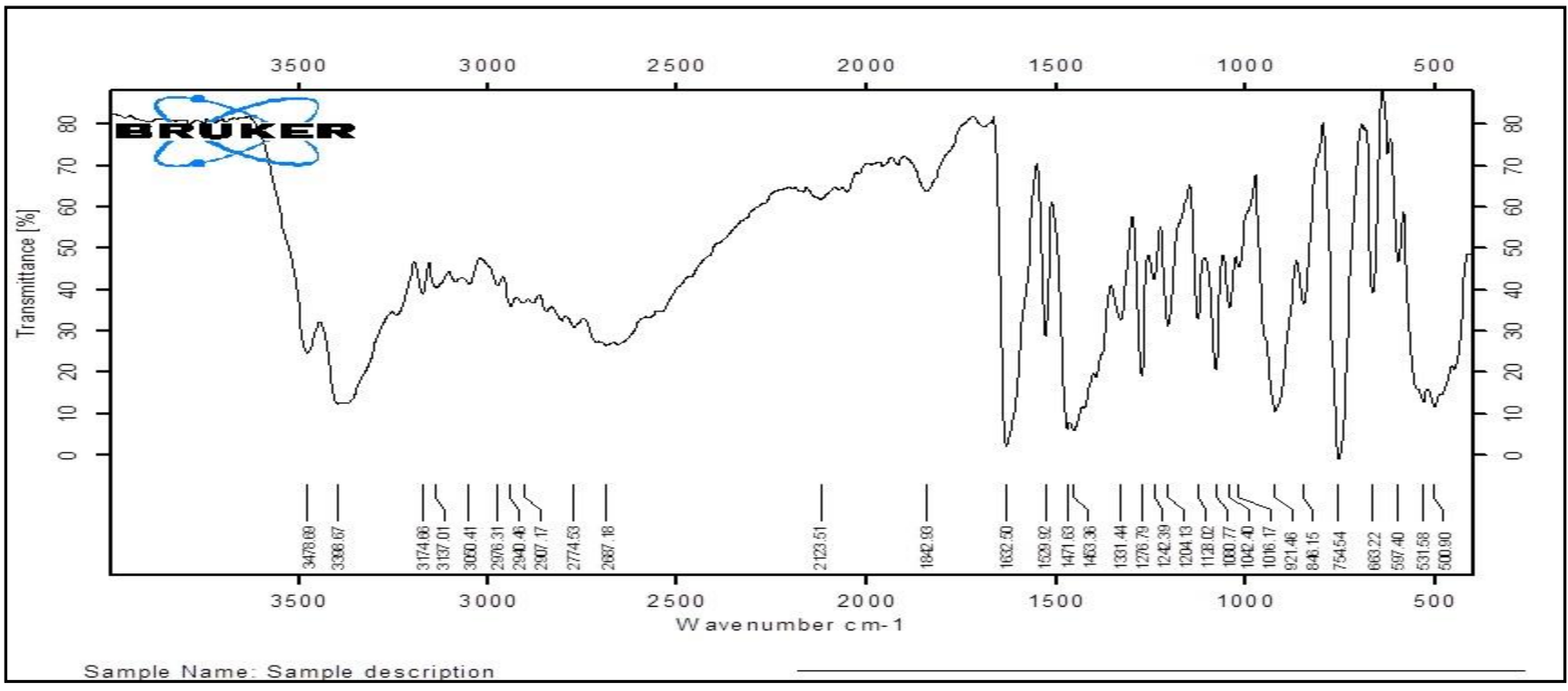

Figure 9. FTIR spectra of OND pure drug

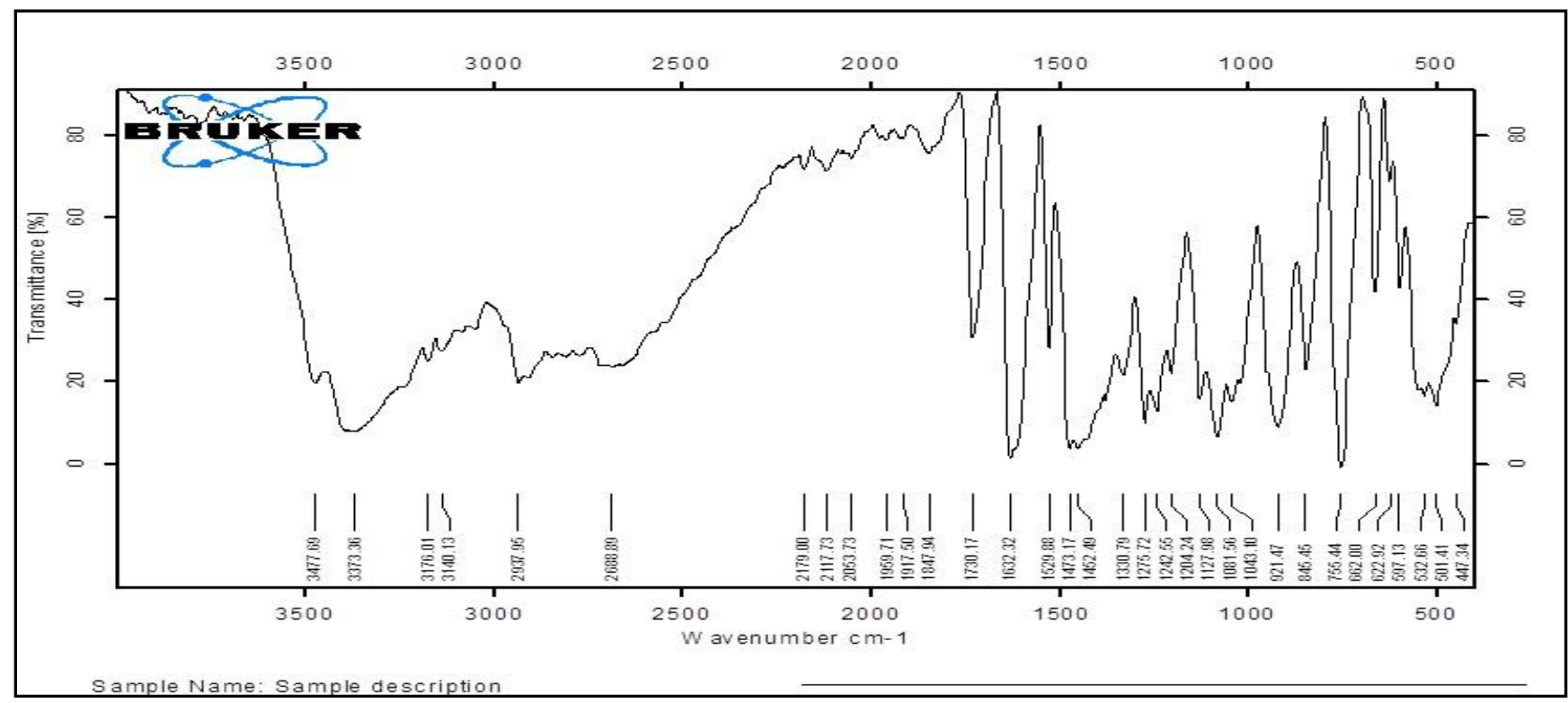

Figure 10. FTIR spectra of (OND and PVA) physical mixture 


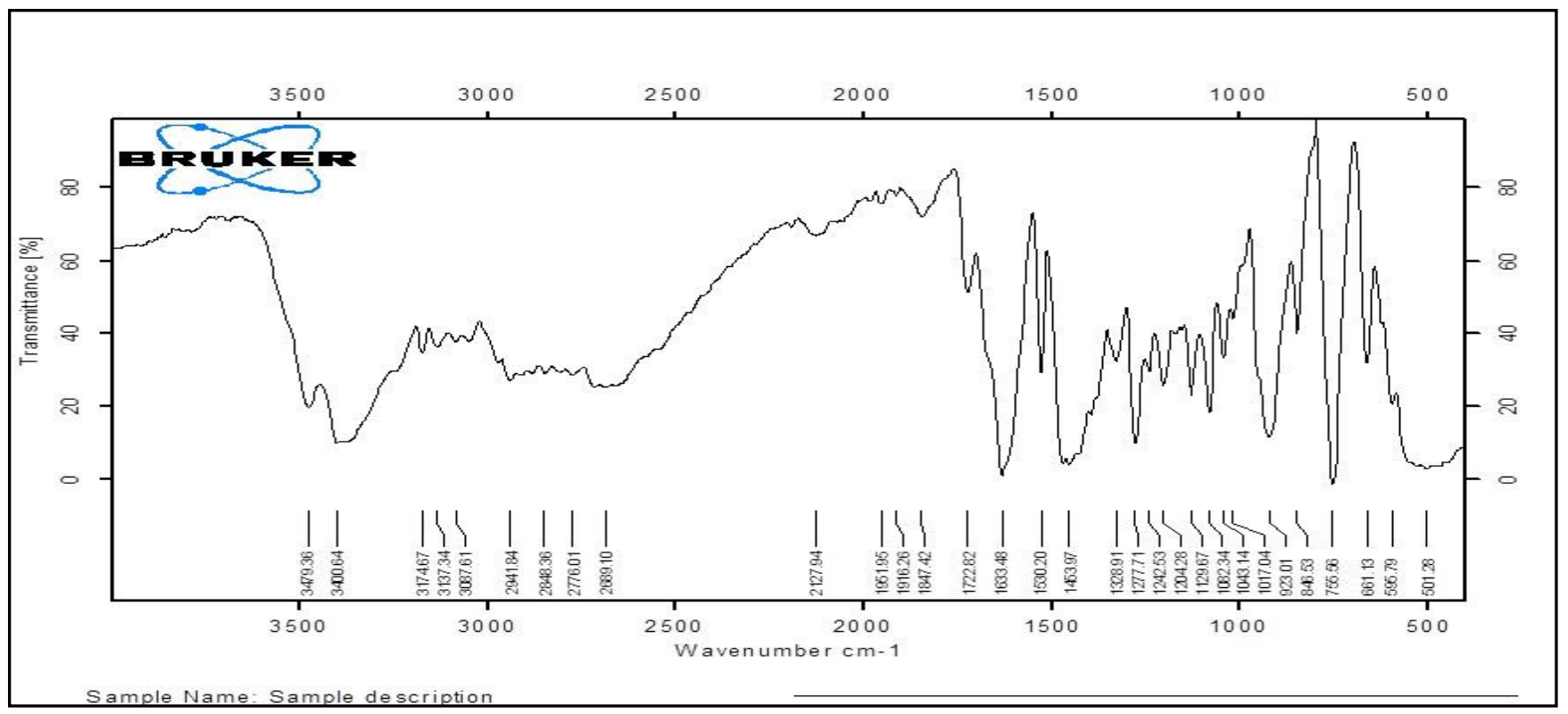

Figure 11. FTIR spectra of (OND and Eudragit RS 100) physical mixture

\section{Conclusion}

Ondansetron $\mathrm{HCl}$ nanoparticles were prepared successfully using nanoprecipitation method. Drug: Polymer ratio of the system were important to obtain nanoparticles with desired size. The encapsulation efficiencies were acceptable for all nanoparticles obtained. The release profile of the drug from nanoparticles were dependent on the type and concentration of the used polymers and the transdermal permeation study show that nanoparticles permeate efficiently than aqueous solution of the drug through the skin by approximately two fold. The controlled drug release of OND aimed for transdermal drug delivery could be obtained by using eudragit RS100 and eudragit RL100 polymers which can reduce dosing frequency, decrease side effects and improve patient compliance. The prepared OND nanoparticles will be introduced in transdermal microneedle patches in part two of this research.

\section{Acknowledgment}

We extend our appreciation to the University of Baghdad, College of Pharmacy for granting this research project.

\section{Conflict of Interests}

\section{Declared None}

\section{References}

1. Gupta R, Rai B. In-silico design of nanoparticles for transdermal drug delivery application. Nanoscale. 2018;10(10):4940-51.

2. Contri RV, Fiel LA, Alnasif N, Pohlmann AR,Guterres SS, Schäfer-Korting M. Skin penetration and ermal tolerability of acrylic nanocapsules: Influence of the surface charge and a chitosan gel used as vehicle International journal of pharmaceutics. 2016;507(1-2):12-20.
3. Balzus B, Sahle FF, Hönzke S, Gerecke C, Schumacher F, Hedtrich S, et al. Formulation and ex vivo evaluation of polymeric nanoparticles for controlled delivery of corticosteroids to the skin and the corneal epithelium. European Journal of Pharmaceutics and Biopharmaceutics. 2017;115:122-30.

4. Latheeshjlal L, Phanitejaswini P, Soujanya Y, Swapna U, Sarika V, Moulika G. Transdermal drug delivery systems: an overview. International Journal of PharmTech Research. 2011;3(4):2140-8.

5. Uchechi O, Ogbonna JD, Attama AA. Nanoparticles for dermal and transdermal drug delivery. Application of Nanotechnology in Drug Delivery: IntechOpen; 2014.

6. Uchechi O, Ogbonna JD, Attama AA. Nanoparticles for dermal and transdermal drug delivery. Application of Nanotechnology in Drug Delivery: IntechOpen; 2014.

7. Latheeshjlal.L PP, Y.Soujanya, U.Swapna, V.Sarika GM. Transdermal Drug Delivery Systems: An Overview. International Journal of PharmTech Research. 2011;3(4):9.

8. Bala $P$, Jathar $S$, Kale $S$, Pal K. Transdermal Drug Delivery System (TDDS)-A Multifaceted Approach For Drug Delivery. Journal of Pharmacy Research. 2014;8(12):1805-35.

9. Koland M, Charyulu RN, Vijayanarayana K, Prabhu P. In vitro and in vivo evaluation of chitosan buccal films of ondansetron hydrochloride. International journal of pharmaceutical investigation. 2011;1(3):164.

10. Patel DR, Joshi A, Patel HH, Stagni G. Development and in-vivo evaluation of ondansetron gels for transdermal delivery. Drug development and industrial pharmacy. 2015;41(6):1030-6. 
11. Pignatello $R$, Bucolo $C$, Ferrara $P$, Maltese A, Puleo A, Puglisi G. Eudragit RS100® nanosuspensions for the ophthalmic controlled delivery of ibuprofen. European Journal of Pharmaceutical Sciences. 2002;16(1-2):53-61.

12. Al-lami MS, Oudah MH, Rahi FA. Preparation and characterization of domperidone nanoparticles for dissolution improvement. Iraqi Journal of Pharmaceutical Sciences (P-ISSN: 1683-3597, EISSN: 2521-3512). 2018;27(1):39-52.

13. Joshi AS, Patel HS, Belgamwar VS, Agrawal A, Tekade AR. Solid lipid nanoparticles of ondansetron $\mathrm{HCl}$ for intranasal delivery: development, optimization and evaluation. Journal of Materials Science: Materials in Medicine. 2012;23(9):2163-75.

14. Sreelola V, Sailaja AK, Pharmacy M. Preparation and characterisation of ibuprofen loaded polymeric nanoparticles by solvent evaporation technique. Int J Pharm Pharm Sci. 2014;6(8):416-21.

15. Hussein A. Darifenacin Hydrobromide loaded nanostructured lipid carrier for oral administration. Iraqi Journal of Pharmaceutical Sciences (P-ISSN: 1683-3597, E -ISSN: 2521-3512). 2018;27(1):53-68.

16. Jana U, Mohanty AK, Pal S, Manna PK, Mohanta GP. Preparation and in vitro characterization of Felodipine loaded Eudragit ${ }^{\circledR}$ RS100 nanoparticles. Int J Pharm Pharm Sci. 2014;6:564-7.

17. Archna SSG, Manoj Kumar Mishra, Raj Keshwar Prasad. Formulation and Characterization of Ketorolac Tromethamine Nanoparticle with Eudragit RS-100 and RL100 by Nano precipitation Method. International Journal of Research in Pharmacy and Biosciences. 2018;4(1):17-23.

18. Gwak HS, Oh IS, Chun IK. Transdermal delivery of ondansetron hydrochloride: effects of vehicles and penetration enhancers. Drug development and industrial pharmacy. 2004;30(2):187-94.

19. Selvaraj S, Niraimathi V. Formulation and in vivo Evaluation of Acyclovir Loaded Chitosan Nanoparticles for Ocular Delivery. International Journal of Pharmaceutical Sciences and Drug Research. 2017;9(3):11825 .

20. Shailendra B, Priti T. Taste masking of Ondansetron Hydrochloride and formulation of fast dissolving tablets. J Chem Pharm Res. 2011;3(4):472-84.
21. Kharb V, Saharan VA, Dev K, Jadhav H, Purohit S. Formulation, evaluation and 32 full factorial design-based optimization of ondansetron hydrochloride incorporated taste masked microspheres. Pharmaceutical development and technology. 2014;19(7):83952.

22. Palmer BC, DeLouise LA. Nanoparticleenabled transdermal drug delivery systems for enhanced dose control and tissue targeting. Molecules. 2016;21(12):1719.

23. El-Nahas AE, Allam AN, Abdelmonsif DA, El-Kamel AH. Silymarin-loaded eudragit nanoparticles: formulation, characterization, and hepatoprotective and toxicity evaluation. Aaps Pharmscitech. 2017;18(8):3076-86.

24. Cetin M, Atila A, Kadioglu Y. Formulation and in vitro characterization of Eudragit $\AA$ L100 and Eudragit ${ }^{\circledR}$ L100-PLGA nanoparticles containing diclofenac sodium. Aaps Pharmscitech. 2010;11(3):1250-6.

25. Aisha AF, Abdulmajid AMS, Ismail Z, Alrokayan SA, Abu-Salah KM. Development of polymeric nanoparticles of Garcinia mangostana xanthones in eudragit RL100/RS100 for anti-colon cancer drug delivery. Journal of Nanomaterials. 2015;16(1):385.

26. Haznedar S, Dortunc B. Preparation and in vitro evaluation of Eudragit microspheres containing acetazolamide. International journal of pharmaceutics. 2004;269(1):13140.

27. Yu Q, Wu X, Zhu Q, Wu W, Chen Z, Li Y, et al. Enhanced transdermal delivery of meloxicam by nanocrystals: Preparation, in vitro and in vivo evaluation. Asian journal of pharmaceutical sciences. 2018;13(6):518-26.

28. Anilkumar A. Formulation of Ondansetron $\mathrm{HCl}$ Matrix Tablets with Microenvironmental $\mathrm{pH}$ Modifier for Improved Dissolution and Bioavailability under Hypochlorhydria. Asian Journal of Pharmaceutics (AJP): Free full text articles from Asian J Pharm. 2016;10(3).

29. Pattnaik S, Swain K, Mallick S, Lin Z. Effect of casting solvent on crystallinity of ondansetron in transdermal films. International journal of pharmaceutics. 2011;406(1-2):106-10. 